\title{
argestre
}

\section{Promoção do aleitamento materno e da doação de leite humano em um grupo de apoio virtual}

\author{
PROMOTION OF BREASTFEEDING AND HUMAN MILK DONATION IN A VIRTUAL SUPPORT \\ GROUP
}

Raquel Medeiros Bastos Roriz Barbo', Ida Helena Carvalho Francescantonio Menezes², Karine Anusca Martins ${ }^{3}$

\author{
1 Mestrado Profissional em Ensino na Saúde. \\ Universidade Federal de Goiás. \\ ORCID: https://orcid.org/0000-0002-9056-5501 \\ Email: nutriraquelbastos@gmail.com \\ 2 Doutora em Ciências. Universidade Federal de Goiás. \\ ORCID: https://orcid.org/0000-0003-4214-7206 \\ Email: idahelenamenezes@gmail.com \\ 3 Doutora em Ciências da Saúde. Universidade Federal \\ de Goiás. \\ ORCID: https://orcid.org/0000-0003-4992-4522 \\ Email: karineanusca@gmail.com
}

Correspondência: Rua 235 esq. com $5^{a}$ Avenida s/n Setor Universitário - Goiânia, GO, Brasil. CEP 74605-050.

Copyright: Esta obra está licenciada com uma Licença Creative Commons Atribuição-Não Comercial 4.0 Internacional.

Conflito de interesses: os autores declaram que não há conflito de interesses.

\section{Como citar este artigo}

Barbo RMBR; Menezes IHCF; Martins KA. Promoção do aleitamento materno e da doação de leite humano em um grupo de apoio virtual. Revista de Saúde Digital e Tecnologias Educacionais. [online], volume 5, n. 3. Editor responsável: Luiz Roberto de Oliveira. Fortaleza, dezembro de 2020, p. 01-19. Disponível em: http://periodicos.ufc.br/resdite/index. Acesso em "dia/mês/ano".
Data de recebimento do artigo: $12 / 10 / 2020$

Data de aprovação do artigo: 14/09/2020

Data de publicação: 31/12/2020

\section{Resumo}

Objetivo: Analisar um grupo em uma rede social virtual (WhatsApp $\AA$ ) como estratégia para fortalecer a prática de amamentação e doação de leite humano. Método: Estudo qualitativo de intervenção com uma amostra intencional composta por 24 doadoras de leite humano. Durante três meses, foram compartilhados conteúdos conforme temas definidos por uma entrevista inicial. Ao final da intervenção, realizaram-se entrevistas semiestruturadas para avaliar o processo educativo mediado pelo WhatsApp ${ }^{\circledR}$. Adotou-se a modalidade temática da análise de conteúdo. A ação educativa fundamentou-se nos seguintes princípios de Paulo Freire: rigor científico, ética, diálogo, respeito à sabedoria e à vivência prática das participantes. Resultados: Dois núcleos temáticos foram evidenciados com a análise: "As expectativas em relação a um grupo virtual de apoio à amamentação" e "A experiência em um grupo virtual de apoio à amamentação". A expectativa das mães com o grupo consistia em resolver as suas dificuldades com a amamentação e em apoiar outras mães. 0 grupo revelou a possibilidade de aprendizagem, trocas e estímulo à doação. Conclusão: 0 grupo na rede social fortaleceu a prática da amamentação, 
promoveu aprendizado, apoio à amamentação e estímulo à doação de leite humano, conforme as percepções das participantes.

Palavras-chave: Aplicativos Móveis.

Aleitamento Materno. Bancos de leite.

\section{Abstract}

Objective: To analyze a group on a virtual social network (WhatsApp®) as a strategy to strengthen the practice of breastfeeding and human milk donation. Method: Qualitative intervention study with an intentional sample composed of 24 human milk donors. For three months, some contents were shared according to the themes defined by an initial interview. At the end of the intervention, some semistructured interviews were conducted to assess the educational process mediated by WhatsApp $B$. A thematic modality of content analysis was adopted. The educational action was based on the following principles of Paulo Freire: scientific rigor, ethics, dialogue and respect for the wisdom and practical experience of the participants. Results: Two thematic groups were evidenced from the analysis: "The expectations towards a virtual breastfeeding support group" and "The experience in a virtual group on breastfeeding". The expectation of mothers with the group consisted in resolving their difficulties with breastfeeding and supporting other mothers. The group revealed the possibility of learning, exchanging and encouraging donation. Conclusion: The group on the virtual social network strengthened the practice of breastfeeding, promoted learning, supported breastfeeding and encouraged the donation of human milk, according to the participants' perception.

Keywords: Mobile applications. Breastfeeding. Milk banks.

\section{Introdução}

O aleitamento é a intervenção mais efetiva para a redução da morbimortalidade infantil1. Apesar das evidências dos benefícios do aleitamento materno (AM) e das recomendações da Organização Mundial da Saúde (OMS), no Brasil, em 2013, apenas 36,8\% das crianças eram amamentadas exclusivamente até o sexto mês de vida².

$O$ avanço nas pesquisas que reforçam as vantagens da amamentação não consegue impedir a prática do desmame, que se caracteriza como um fenômeno multidimensional, influenciado pela cultura, interesses econômicos e comportamentos sociais. ${ }^{3}$ São muitos os desafios à amamentação, como o retorno precoce das mães ao trabalho, ambiente que não incentiva a amamentação, as orientações inadequadas de profissionais de saúde, a introdução alimentar precoce, a indicação incorreta de fórmulas infantis e de alimentos complementares. ${ }^{3}$ Ainda comprometem a prática amamentar a dor, os mamilos feridos, a pega inadequada, o uso de chupetas e de bicos artificiais, mitos e as influências negativas do marketing dos substitutos do leite humano ${ }^{3}$.

As indústrias de substitutos do leite humano se apropriaram das mídias sociais virtuais para a comercialização de fórmulas e alimentos infantis. São claras as violações à Norma Brasileira de Comercialização de Alimentos para Lactentes (NBCAL), compreendendo desde o fornecimento de descontos até a propaganda por meio de blogs pessoais ${ }^{4}$. 
Reduzir o desmame em um momento em que as indústrias de fórmulas infantis se fazem cada vez mais presentes por meio da internet é desafiador. 0 advento das redes sociais trouxe novas dificuldades para a promoção do $\mathrm{AM}$, mas também contribuiu com ferramentas singulares que podem ser melhor exploradas, como, por exemplo, a criação de grupos virtuais de apoio à amamentação. Os Bancos de Leite Humanos (BLHs) mostram-se como unidades fundamentais para esse tipo de intervenção educativa em grupos virtuais.

As ações realizadas por meio dos BHLs nas maternidades, associada à Iniciativa Hospital Amigo da Criança (IHAC), como o aconselhamento e o suporte imediato à amamentação no pós-parto, exerce influências positivas na prevalência da amamentação" 5, 6. Além do apoio ao AM, os BLHs têm a função de coletar e distribuir leite humano com padrão de qualidade para a alimentação de recém-nascidos em risco e, desta forma, reduzir a mortalidade infantil 7 . A doação está diretamente relacionada ao apoio e às orientações recebidos nos BLHs e nas unidades de saúde. Outrossim, essa assistência impacta na captação de novas doadoras ${ }^{8}$.

Observa-se que tanto a promoção do AM quanto a doação de leite humano podem ser incentivadas por meio da formação de grupos de apoio/aconselhamento. Evidências comprovam que tais grupos favorecem o início oportuno da amamentação ${ }^{9}$. Ações educativas com grupos de doadoras de leite humano aumentaram o número e o volume de leite coletado ${ }^{10}$. Grupos de apoio virtuais também podem exercer uma influência positiva sobre a amamentação, contudo, o número limitado de estudos nessa área impede a avaliação desse impacto ${ }^{11}$.

A internet é uma importante fonte de informação em saúde ${ }^{12}$. 0 acesso a essa tecnologia ampliou-se com a possibilidade da sua utilização por intermédio do aparelho celular. No ano de 2016, o percentual dos domicílios brasileiros com acesso à internet por telefone chegou à $92,1 \%{ }^{13}$.

O presente estudo justifica-se pelo avanço na utilização da internet e de redes sociais virtuais em celulares ${ }^{13}$, na busca por informação sobre saúde ${ }^{14} \mathrm{e}$ no potencial de grupos de apoio virtuais na construção do conhecimento e na autonomia de amamentação para as mães participantes ${ }^{15}$.

O objetivo deste artigo consistiu em analisar um grupo em uma rede social virtual (WhatsApp ${ }^{\circledR}$ ) como estratégia para fortalecer a prática da amamentação e a doação de leite humano. 


\section{Métodos}

Este trabalho apoia-se em uma pesquisa qualitativa de intervenção com uma amostra intencional, a qual envolveu o planejamento e a implementação de uma ação educativa destinada a dar apoio e promover a amamentação e a doação de leite humano, com a posterior avaliação de seus efeitos.

Analisou-se e interpretou-se a experiência de doadoras de um BLH no município de Goiânia, vinculado à maternidade Hospital Amigo da Criança (HAC). As doadoras foram convidadas, por telefone ou presencialmente, a participar de um grupo no WhatsApp. 0 estudo foi conduzido durante sete meses por uma equipe de pesquisa treinada e composta pela pesquisadora principal, nutricionista e consultora em amamentação, e por voluntárias, alunas do curso de nutrição, conforme as etapas apresentadas no Quadro 1. As participantes não tiveram relacionamento prévio com as pesquisadoras.

Quadro 1. Fases do estudo.

\begin{tabular}{|l|l|}
\hline 1 & $\begin{array}{l}\text { Seleção: convite às participantes e realização da primeira fase de entrevistas, com objetivo } \\
\text { de identificar as expectativas das doadoras de leite humano em relação a um grupo de } \\
\text { WhatsApp sobre amamentação (dois meses). }\end{array}$ \\
\hline 2 & $\begin{array}{l}\text { Intervenção: criação do grupo de WhatsApp e publicação de postagens com vistas a } \\
\text { promover o AM e a doação de leite humano (três meses). }\end{array}$ \\
\hline 3 & $\begin{array}{l}\text { Entrevistas semiestruturadas: após a intervenção, entrevistas cujo intuito foi verificar a } \\
\text { percepção das doadoras sobre a sua participação no grupo virtual (dois meses). }\end{array}$ \\
\hline
\end{tabular}

Fonte: elaborado pelos autores, 2018.

Realizou-se um estudo piloto com seis puérperas a fim de testar o instrumento (questionário) e observou-se a necessidade de conhecer a experiência prévia com a amamentação e as formas de superação das dificuldades encontradas.

$\mathrm{Na}$ primeira fase do estudo, o critério de exclusão consistiu em não possuir o WhatsApp. Das 89 mulheres maiores de 18 anos, que estavam cadastradas no BLH no período, apenas duas não possuíam o aplicativo, uma perdeu o bebê e 32 não foram localizadas. 0 grupo foi composto por 54 doadoras, e 14 entrevistadas.

Utilizou-se a técnica de análise de conteúdos temáticos proposta por Bardin ${ }^{16}$. A coleta, em cada etapa, foi interrompida quando observado o ponto de saturação: momento no qual se inicia a redundância dos temas ou a repetição das informações ${ }^{17}$.

A segunda fase foi caracterizada pela intervenção no grupo do WhatsApp por meio de postagens sobre os temas selecionados, publicadas no grupo semanalmente, durante 12 semanas, com um rigoroso acompanhamento dos diálogos e das normas do grupo. A 
participação foi estimulada por meio de perguntas provocativas sobre cada tema. Concluíram a participação nesta etapa 24 participantes.

A terceira fase teve como critério de inclusão a conclusão de todo o período da intervenção. Dez participantes foram entrevistadas até o ponto de saturação ser atingido. As entrevistas, tanto na primeira quanto na terceira fase, tiveram lugar no domicílio da doadora ou no banco de leite. O roteiro foi composto por duas partes: caracterização sociodemográfica e questões norteadoras específicas a cada fase. As gravações foram efetivadas por dois membros da equipe de pesquisa.

Dentre os procedimentos metodológicos, foram utilizadas notas dos pesquisadores e optou-se por não adotar nenhum software de apoio à análise de conteúdo. Dentre as atividades exercidas, destacam-se: a transcrição das entrevistas, a pré-análise com leitura flutuante, a leitura exaustiva e a identificação dos temas, a descrição e a organização em núcleos temáticos e a interpretação dos resultados, embasada pelo referencial teórico adotado $^{18,19}$.

Os núcleos temáticos e as categorias estabelecidos por intermédio da análise dos dados estão representados no Quadro 2.

Quadro 2. Categorias e grupos temáticos.

\begin{tabular}{|c|l|}
\hline Primeiro Núcleo temático & Expectativas em relação a um grupo virtual de apoio à amamentação \\
\hline Categoria 1 & As dificuldades com a técnica e com o manejo da amamentação \\
\hline Categoria 2 & Estratégias de superação dessas dificuldades \\
\hline Categoria 3 & Os temas de interesse para o grupo virtual \\
\hline Segundo Núcleo temático & Experiências em um grupo virtual de apoio à amamentação \\
\hline Categoria 1 & As impressões com a estratégia utilizada, o WhatsApp \\
\hline Categoria 2 & Os aprendizados com o grupo \\
\hline Categoria 3 & As trocas de experiências entre as participantes \\
\hline Categoria 4 & O estímulo à doação promovido pelo grupo \\
\hline
\end{tabular}


\begin{tabular}{|l|l|} 
Categoria 5 & Sugestões das participantes para a manutenção do grupo \\
\hline
\end{tabular}

Fonte: elaborado pelos autores, 2018.

O estudo atendeu às exigências da Resolução n. 466 de 12 de dezembro de 2012 do Conselho Nacional de Saúde, com aprovação do Comitê de Ética e Pesquisa da Universidade Federal de Goiás (UFG) sob parecer 2.439682. Além disso, as participantes assinaram um Termo de Consentimento Livre e Esclarecido (TCLE).

\section{Resultados}

Das 24 participantes, mais de 60\% cursaram o ensino médio completo ou superior, 18 eram primíparas (75\%), todas realizaram o pré-natal (100\%) e 18 fizeram o parto na rede pública (75\%). Muitas (66\%) não receberam informações sobre o AM durante o pré-natal, o que é considerado preocupante. Os dados são apresentados na Tabela 1 presente no anexo.

\section{As expectativas em relação ao grupo virtual de apoio à amamentação}

As doadoras de leite humano esperavam que o grupo divulgasse informações conforme os temas sugeridos e que favorecesse as trocas de experiências. Além da reflexão sobre sua realidade, necessidade e contribuição para superar as suas dificuldades e a de outras mães com a amamentação.

\section{As dificuldades com o manejo da amamentação}

As dificuldades com a amamentação relacionaram-se a questões biológicas, próprias do manejo da amamentação, tais como dor, dificuldades com a pega, ferimentos e sensação de mama cheia:

"A maior dificuldade que eu tenho foi o bico de peito ferido, porque machucou demais." (D167)

"Tive, a pega, para a boquinha encaixar certinho, então meu peito feriu. No começo doía muito, machucou, era horrível dar mama para ela." (D380)

".. é que como eu sempre tive muito leite empedrou né aí eu tive mastite" (D301)

\section{Estratégias de superação das dificuldades com a amamentação}


Foram observadas diferentes estratégias de superação: o esforço pessoal e o apoio de outras mães, da maternidade e do banco de leite. No entanto, algumas não fizeram referência a qualquer outro tipo de suporte que promovesse o apoio: amigos, família ou instituições. Isso pode demonstrar que desconhecem o momento certo ou os locais onde buscar ajuda:

“Sozinha, porque não tinha ninguém para ajudar ou orientar." (D01)

Outrossim, verificou-se que ter apoio de outras mães com experiência pode beneficiar a amamentação, seja de forma presencial seja por meio de grupos de mães em redes sociais virtuais:

"O meu marido tem uma tia que fez um curso lá na maternidade que a neném dela nasceu prematura, aí ela que me ensinou a fazer a pegada certinha." (D445)

"[...] me indicaram que tem um grupo (WhatsApp) das doulandas e das doulas que qualquer coisa que eu perguntava já vinha todo um currículo de experiência para auxiliar: 'olha faz isso', 'com a minha filha deu certo com isso'." (D02)

Observa-se que o apoio de mães e de grupos virtuais foi referido como positivo, mas também pode refletir um problema quando a plataforma é utilizada para reforçar mitos ou para ressaltar a cultura da dor na amamentação como algo natural.

O suporte de profissionais de saúde foi bastante presente, devido aos partos terem ocorrido no HAC e ao apoio à amamentação oferecido pelo banco de leite:

"Eu consultei no banco de leite e fui orientada vamos ver se agora daqui pra frente, ele pega normalzinho." (D03)

"Eu ganhei ela aqui (maternidade), aí como eu tive dificuldade de dar mamar, porque no começo eu estava dando só o bico aí as meninas foram me ensinar tudo. Eu cheguei até o banco de leite com as meninas daqui me ensinando a amamentar." (D216)

\section{Os temas de interesse do grupo}

Identificou-se uma preocupação das participantes em resolver as suas próprias dificuldades durante a amamentação e em oferecer amparo solidário às outras mães. Os temas sugeridos manifestaram-se em questões práticas relacionadas ao manejo da 
amamentação, à alimentação, aos cuidados com os bebês e aos mitos sobre a amamentação:

"Pode ser essa questão de o bebê não pegar nos primeiros dias, essas dificuldades de pegar e amamentar." (D02)

"As formas de ajudar assim na cicatrização do peito, que às vezes machuca muito e às vezes tem mãe que não sabe o que fazer também." (D167)

"Para ensinar a tirar o leite mesmo, por causa que foi tão difícil pra mim, eu sofri tanto e eu poderia ter evitado isso né?" (D301)

"Muitas mães também sofrem com aquele negócio das pessoas ficarem falando que o leite não sustenta essas coisas eu acho também que é um assunto que vai ajudar muita gente." (D445)

"Sobre a gente, alimentação da gente, das mães." (D420)

A fala das mães reforça que o interesse pelo aprendizado despertou alguns "problemas" práticos que surgiram com a amamentação. A partir de então, foram evidenciados os temas geradores das publicações no grupo de WhatsApp conforme o Quadro 3.

Quadro 3. Temas publicados no grupo do WhatsApp.

\begin{tabular}{|l|}
\hline \multicolumn{1}{|c|}{ Temas } \\
\hline Tema 1 - Expectativa x realidade na amamentação \\
\hline Tema 2 - Pega e posição \\
\hline Tema 3 - Tratamento de fissuras \\
\hline Tema 4 - Fisiologia da lactação \\
\hline Tema 5 - Doação de leite \\
\hline Tema 6 - Alimentação da nutriz \\
\hline Tema 7 - Estratégias para aumentar a produção leite \\
\hline Tema 8 - Aspectos emocionais do puerpério \\
\hline Tema 9 - Cuidados com o bebê \\
\hline Tema 10 - Alimentação complementar \\
\hline Tema 11 - Mitos sobre a amamentação \\
\hline Tema 12 - Leis da amamentação e publicidade na internet \\
\hline
\end{tabular}

Fonte: elaborado pelos autores, 2018. 


\section{As experiências em um grupo virtual de apoio à amamentação}

A participação no grupo fortaleceu a prática da amamentação à medida em que promoveu trocas de experiências, aprendizado e estímulo à doação.

\section{As impressões com a estratégia utilizada: o WhatsApp}

As doadoras apontaram alguns benefícios da estratégia como a praticidade, a rapidez no atendimento às dúvidas e a facilidade no acesso à informação.

"Acho bom, é prático né, porque hoje em dia ninguém tem tempo" (D111)

"Foi bem pensado, porque o WhatsApp ele é muito utilizado hoje, porque tem gente que não para para ler papel nem nada, mas uma mensagem no WhatsApp todo mundo vai parar para ler" (D325)

\section{Aprendizados com o grupo}

Evidenciam-se aspectos de que o conhecimento construído por meio do grupo estimulou a reflexão crítica e mudanças de práticas. 0 aprendizado contribuiu para o conhecimento de aspectos importantes nos cuidados com o leite doado e para a introdução da alimentação complementar, uma vez que esses foram os temas de destaque na fala das participantes. Um vídeo foi publicado como forma de exemplificar as técnicas de extração manual e estocagem domiciliar de leite humano. A postagem foi mencionada como importante nesse processo:

"Com certeza muda muita coisa, a gente faz de um jeito, vê no grupo começa a fazer de outro jeito que a gente acha melhor" (D325)

"Justamente o vídeo, porque eu fazia errado né, no caso, aí eu comecei a fazer certinho" (D450)

"Vocês postaram um também sobre alimentação né? Que eu achei bem bom também. [...] acho que aprendi" (D436) 


\section{Trocas de experiência}

As nutrizes perceberam as suas participações no grupo como importantes. Observa-se o desvelamento crítico e o aumento da autonomia, pois elas passaram a se notar como capazes de oferecer e receber apoio, incentivo e ensinamentos:

"Para mim foi completo... Eu ajudei, eu fui ajudada... Eu aprendi, eu ensinei. [...] teve algumas questões no grupo que algumas mãezinhas perguntavam que eu até ajudava de acordo com a minha experiência eu repassei" (D398)

"Eu achei muito importante o grupo por causa disso, porque uma pode ajudar a outra e às vezes a gente não sofre tanto né?" (D230)

\section{Estímulo à doação}

Destacou-se no grupo a promoção da doação de leite humano, devido ao aprendizado de novas técnicas de extração e ao estímulo da doação por meio dos relatos de mães de bebês receptores concernentes à importância e ao volume de leite humano para alimentar um prematuro:

"Toda vez vocês colocam bebês que foram ajudados que eu acho que isso estimula muito a gente, que a gente fala assim: nossa realmente eu estou ajudando uma pessoa." (D301)

"Mas aí quando eu descobri que $300 \mathrm{ml}, 400 \mathrm{ml}$ de leite ajuda muito, aí eu fique mais animada né? Para doar." (D398)

"Eu doava [...] eu tenho a maquininha manual [...] mas aí vocês mostraram lá como que tirava na mão e eu não dava conta, aí depois do vídeo que eu consegui mesmo" (D436)

\section{Discussão}

Um maior conhecimento e esclarecimento entre as mães sobre o AM, como observado nesse estudo, pode ser um fator de proteção da amamentação e de favorecimento da doação de leite humano. A evolução da escolaridade materna está relacionada à melhora dos indicadores de amamentação no Brasil $^{20}$ e pode influenciar a manutenção do comportamento de doação de leite ${ }^{21}$. 
Serem primíparas e não terem recebido informações sobre o AM durante o pré-natal são fatores de risco para o desmame. Gestantes que receberam orientações apresentam maiores chances de promover um início oportuno da amamentação, ou seja, na primeira hora de vida, ${ }^{21}$ e de amamentar até os seis meses. A atenção básica deve, portanto, orientálas sobre os benefícios e sobre o manejo do AM. Ademais, os profissionais em saúde devem possuir formação adequada para essa prática ${ }^{22}$.

Ressalta-se na literatura a importância de que as ações de apoio, promoção e proteção do aleitamento sejam realizadas de forma contínua, iniciadas no pré-natal, reforçadas na internação e mantidas após a alta hospitalar ${ }^{1,12,22,23,24}$.

A falta de informação no pré-natal, observada no grupo estudado, pode indicar a falha na rede do cuidado em amamentação e a necessidade de se reforçar as ações de apoio na atenção básica. Outrossim, as dificuldades de informação podem ter contribuído às dificuldades enfrentadas, as quais motivaram à procura de ajuda do banco de leite. Entre as doadoras, os principais motivos que as levam a buscar o BLH são as complicações com o ingurgitamento mamário, as dificuldades com a pega, a mama cheia, a dor, fissuras ou a percepção de excesso de produção láctea ${ }^{11,25}$. Alguns autores australianos verificaram que os tópicos mais acessados por mães na internet também estão relacionados ao manejo da amamentação ${ }^{26}$.

Os relatos das mulheres deste estudo mostram que, para enfrentar essas dificuldades, foram utilizadas diferentes estratégias de superação, as quais evidenciam que a melhor forma de apoiar o aleitamento materno é por meio da ajuda e do suporte, tanto pelos serviços de saúde quanto pela comunidade. Esse apoio deve ter em vista a capacitação das mulheres para que elas saibam lidar com as principais dificuldades relacionadas à amamentação ${ }^{1,12,27}$. Além disso, outros autores também apontam que o interesse fundamental das mães consiste em resolver questões práticas do manejo da amamentação ${ }^{28,29}$.

Sobre as estratégias de superação, devido às diversas campanhas sobre a temática, normalmente as mulheres querem amamentar, conhecem as suas vantagens e a duração recomendada. Não obstante, precisam de apoio para superar as suas dificuldades, tanto biológicas quanto socioculturais ${ }^{1,28}$. A falta de suporte pode levar ao fracasso na amamentação, seguido por um sentimento de culpa por parte da mulher ${ }^{29}$.

0 apoio de pessoas próximas, citado pelas participantes, apresenta impactos positivos quando incentiva a prática do AM. Dessa forma, a atenção dos familiares e amigos contribui 
para aumentar a confiança na amamentação ${ }^{31,32}$ e tem maior relevância quando não há suporte profissional disponível ${ }^{33}$. Destaca-se a integração da família nas ações educativas durante o pré-natal, o parto e o pós-parto como uma forma de melhorar a qualidade do apoio prestado pelos entes próximos.

$\mathrm{O}$ apoio dos profissionais de saúde do BLH e da maternidade também se revelou importante neste estudo, tendo em vista serem estratégias essenciais no incentivo à amamentação. Tais profissionais oferecerem ajuda prática às mães na correção da pega e da posição e esclarecem de forma corretiva e preventiva questões sobre as complicações mamárias ${ }^{34}$. A IHAC foi definida como a estratégia mais eficiente na elevação das prevalências de amamentação ${ }^{11}$. Porém, para alcançar o caráter multidimensional da amamentação, as ações de apoio devem analisar as opiniões, a subjetividade, a individualidade, o contexto familiar e educacional, as preferencias, e os interesses das mulheres a fim de escolher o melhor modelo de assistência à amamentação.

Discutir as dificuldades encontradas e as alternativas de superação utilizadas, observando as várias formas de solucionar um mesmo problema, faz parte da estratégia da problematização e foi empregada como ponto de partida para a intervenção educativa utilizada com o grupo da presente pesquisa. Essa abordagem buscou ir além da simples transmissão de conteúdo, em busca de uma ação educativa emancipatória ${ }^{34,35}$.

Observou-se que as participantes deste estudo, consoante a literatura, apontam vantagens dos grupos virtuais no apoio à amamentação, principalmente pela facilidade de acesso, pelo apoio imediato, pela disponibilidade e pela possibilidade de trocas de experiências $^{37,38}$.

Percebe-se que as pessoas tendem a utilizar as redes sociais para buscar informações e expressar sentimentos, compartilhando-os com outras que vivenciam situações semelhantes. As nutrizes podem beneficiar-se desde que as informações sejam baseadas em evidências, por meio de grupos de apoio virtuais, o que promove uma experiência mais bem-sucedida e tranquila no tocante à amamentação ${ }^{39}$. Compartilhar experiências práticas e expressar dúvidas promoveu um bem-estar, benefícios para a saúde e uma maior segurança ao amamentar ${ }^{40}$.

Os princípios freirianos do rigor científico, ética, diálogo respeito à sabedoria e à vivência prática das participantes foram evidenciados ao longo de toda a ação educativa. Incentivar a troca de experiências no grupo é papel do moderador, que deve atuar como um 
estimulador de debates, com o objetivo de fomentar a interação, na perspectiva de um círculo de cultura, o que evita a transmissão vertical do conteúdo ${ }^{36}$.

Assim, por meio de perguntas provocadoras, as participantes foram levadas a uma reflexão crítica e estimuladas a dividir suas experiências práticas acerca da amamentação e da doação de leite. Ao moderador, não cabe apenas definir os interesses do grupo e apresentar o conteúdo conforme as sugestões das participantes, mas cabe escutar as necessidades do grupo, transformar a linguagem científica em uma linguagem simples, considerar aspectos éticos desde a convivência no grupo até o respeito à história de cada participante. Conteúdo e rigor científico são condições essenciais para a educação, porém o educador não pode apenas transferir o seu conhecimento ${ }^{35}$.

A ação educativa realizada levou as participantes a uma reflexão crítica sobre as suas práticas, por meio do diálogo, das trocas de experiências, dos conteúdos compartilhados, do respeito, da escuta e da valorização de suas sabedorias. Quanto às regras de funcionamento, as interações foram mantidas por meio do acompanhamento contínuo do cumprimento das normas sem autoritarismo ${ }^{35}$.

Em um outro estudo, que analisou comentários de mães australianas em grupos fechados do Facebook, os autores também discutiram a postura de "facilitador" adotada por moderadores treinados, o que favoreceu o intercâmbio de informações e possibilitou que as mães aprendessem por elas próprias. Os autores destacam algumas funções do facilitador: oferecer conteúdo baseado em literatura atualizada, incentivar a amamentação, encorajar o diálogo e oferecer ajuda prática ${ }^{27}$.

Em relação ao estímulo da doação de leite, este estudo, em conjunto com a literatura, demonstrou que o fator com maior associação a essa prática é evidenciado pela motivação da mãe em fazer a ordenha na própria mama e armazenar o leite para a doação. As orientações sobre a ordenha estão relacionadas à prática três vezes maiores de doação $0^{9,19}$. 0 presente estudo acrescenta outros aspectos de estímulo à doação: a percepção de que estão ajudando famílias reais e a quantidade de leite suficiente para alimentar o prematuro, quando observam que não é necessário extrair grandes volumes para manter a doação. De igual forma, ações que propiciam o respeito e a valorização dos saberes e das experiências vividas pelas doadoras demonstram um maior impacto na promoção do aleitamento materno e da doação de leite humano ${ }^{24}$.

Tais resultados não devem ser generalizados ou extrapolados para populações com características distintas. Orienta-se que estudos posteriores sobre grupos educativos em 
redes sociais virtuais acerca do AM analisem também os comentários no grupo, o que enriqueceria o universo do conhecimento sobre as impressões, as experiências e as angústias vivenciadas pelas mães.

\section{Conclusão}

A participação das mães em um grupo de uma rede social virtual fortaleceu a prática da amamentação, uma vez que as doadoras de leite humano tiveram um contato com o aprendizado, com o apoio à amamentação e com o estímulo à doação.

Os resultados reforçam a necessidade de se melhorar o cuidado com a amamentação no pré-natal. As gestantes devem ser informadas sobre os benefícios do AM, do manejo da lactação e dos locais onde buscar atendimento em caso de necessidade.

Ampliar a compreensão sobre os determinantes do desmame precoce inicia-se no reconhecimento das dificuldades reais enfrentadas pelas mulheres de forma que este conhecimento guie a formulação de estratégias de promoção do AM mais adequadas às necessidades práticas e às dificuldades concretas das nutrizes.

As redes sociais virtuais facilitam o acesso a informações, a trocas de experiências e ao aprendizado. Propiciam condições para as mães analisarem e decidirem a melhor opção no cuidado com sua própria saúde e com a de seus filhos, o que promove a autonomia e a responsabilidade. Essas atitudes e habilidades são fundamentais para a promoção da amamentação e devem ser incentivadas.

A facilidade e a rapidez no acesso à informação trouxeram satisfação e atenderam às necessidades e às expectativas das participantes. Percebe-se, então, uma tendência social de busca pela agilidade e pela interatividade. Um grupo aos moldes desta pesquisa tem a vantagem adicional de fornecer apoio e escuta de forma qualificada, o que minimiza os riscos de informações inadequadas sem critérios de qualidades bem estabelecidos.

O presente estudo contribuiu ao avanço das pesquisas no campo das redes sociais como estratégia para a promoção da saúde e do AM. Este trabalho demostrou que as redes sociais virtuais apresentam uma estratégia fácil, acessível e com potencial para trazer impacto e contribuir para a ampliação do caráter multidimensional, recomendado para as ações de promoção, proteção, e apoio à amamentação.

Os profissionais de bancos de leites e de maternidades podem formar e manter grupos, nos moldes do sugerido com esta pesquisa, que estimulem a interação e a troca de experiências e que evite a transmissão vertical de conteúdo, como forma de promover apoio 
e estímulo à doação. Os profissionais podem, também, encaminhar as doadoras para grupos já existentes e que forneçam informações de fontes confiáveis e trocas de experiências. Essa estratégia pode contar com a participação de voluntários, até mesmo entre as próprias doadoras, ou com parcerias de universidades.

\section{Agradecimentos}

As autoras gostariam de agradecer à Fundação de Amparo à Pesquisa do Estado de Goiás (FAPEG) pelo apoio financeiro com a oferta de bolsa para o desenvolvimento do mestrado.

\section{Referências}

1. Rollins NC, Bhandari N, Hajeebhoy N, Horton S, Lutter CK, Martines JC, Martines JC, Piwoz EG, Richter, LM, Victora, CG. Why invest, and what it will take to improve breastfeeding practices? Lancet. 2016; 387(10017):491-504.

2. Boccolini CS, Boccolini PMM, Monteiro FR, Venâncio SI, Giugliani ERJ. Tendência de indicadores do aleitamento materno no Brasil em três décadas. Rev de Saude Publica. $2017 ; 51: 1-9$.

3. Almeida JAG, Novak FR. Amamentação: um híbrido natureza-cultura. J Pediatr. 2004; 80(Supl. 5): 119-125.

4. Abrahams SW. Milk and social media: online communities and the International Code of Marketing of Breast-milk Substitutes. J Hum Lact. 2012; 28(3):400-406.

5. Maia PRdS, Almeida JAGd, Novak FR, Silva DAd. Rede Nacional de Bancos de Leite Humano: gênese e evolução. Rev Bras Saude Mater Infant. 2006; 6(3):285-292.

6. Silva CM, Pellegrinelli ALR, Pereira SCL, Passos IR, Santos, LC. Práticas educativas segundo os "Dez passos para o sucesso do aleitamento materno" em um Banco de Leite Humano. Cien Saude Colet. 2017; 22(5):1661-1671. [periódico na internet]. Disponível em https://www.scielosp.org/article/csc/2017.v22n5/1661-1671/.

7. Brasil. Anvisa - Agencia Nacional de Vigilância Sanitária. Bancos de leite humano: funcionamento, prevenção e controle de riscos. Brasília, DF; 2008.

8. Meneses TMXd, Oliveira MICd, Boccolini CS. Prevalence and factors associated with breast milk donation in banks that receive human milk in primary health care units. $J$ Pediatr. 2017; 93(4):382-388.

9. Balogun OO, O'Sullivan EJ, Mcfadden A, Ota E, Gavine A, Garner CD, Renfrew MJ, McGillivray S. Interventions for promoting the initiation of breastfeeding. Cochrane System Rev [periódico online]. 2016; 11. Disponível em:

https://www.cochranelibrary.com/cdsr/doi/10.1002/14651858.CD001688.pub3/full. 10. Pellegrine JB, Koopmans FF, Pessanha HL, Rufino CG, Farias HPSd. Educação Popular em Saúde: doação de leite humano em comunidade do Rio de Janeiro, Brasil. Interface Com, Saude, Educ. 2014; 18 (supl. 2):1499-1506.

11. Sinha B, Chowdhury R, Sankar MJ, Martines J, Taneja S, Mazumder S, Rollins N, Bahl R, Bhandari N. Interventions to improve breastfeeding outcomes: a systematic review and meta-analysis. Acta Pediatr. 2015; 104 (supl. S467): 114-135. 
12. Moretti FA, Oliveira VEd, Silva EMKd. Acesso a informações de saúde na internet: uma questão de saúde pública? Rev Assoc Med Bras. 2012; 58(6):650-658.

13. Brasil. PNAD - Pesquisa Nacional por Amostra de Domicílio. Acesso à internet, à televisão e posse de telefone móvel celular para uso pessoal. [acessado 2017 Dez 08]. Disponível em: http://www.mcti.gov.br/documents/10191/0/pnad-tic-2014.pdf.

14. Laranjo L, Arguel A, Neves AL, Gallagher AM, Kaplan R, Mortimer N, Mendes GA, Lau AYS. The influence of social networking sites on health behavior change: a systematic review and meta-analysis. J Amer Medic Inform Assoc. 2015; 22(1):243-56.

15. Guerra-Reyes L, Christie VM, Prabhakar A, Harris AL, Siek KA. Postpartum Health Information Seeking Using Mobile Phones: Experiences of Low-Income Mothers. Matern and child healt J. 2016;20(Suppl 1):13-21.

16. Bardin L. Análise de conteúdo. São Paulo: Edições 70; 1979.

17. Minayo MCS, Deslandes SF, Gomes R. Pesquisa Social: teoria, métodos e criatividade. Editora Vozes, Petrópoles, 2013.

18. Sousa AFd, Claro MdL, Sousa ALd, Lima LHdO, Santana AGdS. Avanços e desafios do aleitamento materno no Brasil: Uma revisão integrativa. Rev Bras Prom Saude. 2015; 28(3): 434-442.

19. Tong A, Sainsbury P, Craig J. Consolidated criteria for reporting qualitative research (COREQ): a 32-item checklist for interviews and focus groups. Int J Qual Health Care. 2007;19(6):349-357

20. Alencar LCEd, Seidi EMF. Doação de leite humano: experiência de mulheres doadoras. Rev Saude Publica. 2009;43 (1):70-7.

21. Carvalho ML, Boccolini CS, Oliveira MId, Leal MdD. The baby-friendly hospital initiative and breastfeeding at birth in Brazil: a cross sectional study. Reprod Health. 2016; 13 (Supl. 3):208-265.

22. Alves JdS, Oliveira MICd, Rito RVVF. Orientações sobre amamentação na atenção básica de saúde e associação com o aleitamento materno exclusivo. Cien Saude Colet. 2018; 23(4):1661-1671.

23. Péres-Escamilla R, Curry L, Minhas D, Taylor L, Bradley E. Scaling up of Breastfeeding Promotion Programs in Low - and Midle-Income Countries: the "Breastfeeding Gear" Model. Advan in Nutrition. 2012; 2(6):790-800.

24. Nascimento VCd, Oliveira MICd, Herdy V, Silva KSd. Associação entre as orientações pré-natais em aleitamento materno e a satisfação com o apoio para amamentar. Rev Bras de Saude Materno. 2013; 13(2):147-159.

25. Linhares FMP, Pontes CM, Osório MM. Construtos teóricos de Paulo Freire norteando as estratégias de promoção à amamentação. Rev Bras Saude Mater Infant. 2014; 14(4):433-439.

26. Bridges N, Howel G, Schmied V. Exploring breastfeeding support on social media. Internat breastfeeding J. 2018;13(22):1-9.

27. Renfrew MJ. Breastfeeding in the 21st century. Lancet. 2016; 387(10033):2089.

28. Oliveira MICd, Souza IEdO, Santos EMd, Camacho LAB. Avaliação do apoio recebido para amamentar: significados de mulheres usuárias de unidades básicas de saúde do Estado do Rio de Janeiro. Cien Saude Colet. 2010; 15(2):599-608.

29. Fujimori E, Nakamura E, Gomes MM, Jesus LAd, Rezende MA. Aspectos relacionados ao estabelecimento e à manutenção do aleitamento materno exclusivo na perspectiva de mulheres atendidas em uma unidade básica de saúde. Interface - Com, Saude, Educ. 2010; 14(33):315-327.

30. Morgado CMdC, Werneck GL, Hasselmann MH. Rede e apoio social e práticas alimentares de crianças no quarto mês de vida. Cien Saude Colet. 2013; 18(2):367-376. 
31. Kaunonen $M$, Hannula L, Tarkka M-T. Peer support interventions for breastfeeding: a systematic review. J Clin Nurs. 2012 (13-14):1943-1954.

32. Marques ES, Cotta RMM, Magalhães KA, Sant'Ana LFdR, Gomes AP, Siqueira-Batista R. A influência da rede social da nutriz no aleitamento materno: o papel estratégico dos familiares e dos profissionais de saúde. Cien Saude Colet. 2010; 15(Supl. 1):1391-1400. 33. Silva CME, Pellegrinelli ALR, Pereira SCL, Passos IR, Santos LCD. Educational practices in accordance with the "Ten steps to successful breastfeeding" in a Human Milk Bank. Cien Saude Colet. 2017; 22(5):1661-71.

34. Müller FS, Silva IA. Social representations about support for breastfeeding in a group of breastfeeding women. Rev Latino-Am. De Enf. 2009; 17(5):651-657.

35. Brasil. Conselho Nacional de Secretaria de Saúde. Política Nacional da Educação Popular em Saúde. Brasília: DF, 2013.

36. Brandão, CR. O que é o método Paulo Freire. São Paulo, Brasiliense, 1981.

37. Carvalho Sd, Martins Filho J. As relações da família com os pediatras: as visões maternais. Rev paul pediatr. 2016; 34(3):330-335.

38. Lima SGP, Guimarães KMF, Gerhardt PC, Cassiano ACM, Vermelho ACSD, Bortolozzi F. A utilização de redes sociais digitais na área da saúde: uma revisão sistemática. Pesq $\mathrm{e}$ Saude. 2015; 8:79-91.

39. Maia F, Struchiner M. Utilização dos weblogs e de comunidades do orkut como ferramentas pedagógicas em cursos da área da saúde. Interface - Com, Saude, Educ. 2010; 14(35):905-918.

40. Niela-Vilen H, Axelin A, Melender HL, Salantera S. Aiming to be a breastfeeding mother in a neonatal intensive care unit and at home: a thematic analysis of peer-support group discussion in social media. Matern \& child Nutr. 2015; 11(4):712-26. 


\section{Anexos}

Tabela 1. Características sociodemográficas e do período pré e pós-gestacional de doadoras de leite humano. Goiânia/GO, 2018.

\begin{tabular}{|c|c|c|c|}
\hline Caracteristicas & Categorias & $\mathrm{N}(24)$ & $\%$ \\
\hline \multicolumn{4}{|l|}{ Gerais } \\
\hline \multirow[t]{2}{*}{ Idade (anos) } & $<25$ & 9 & 37,5 \\
\hline & $\geq 25$ & 15 & 62,5 \\
\hline \multirow[t]{3}{*}{ Escolaridade } & Ensino Fundamental & 8 & 33,3 \\
\hline & Ensino Médio & 12 & 50,0 \\
\hline & Ensino Superior & 4 & 16,6 \\
\hline \multirow{2}{*}{ Paridade } & Primipara & 18 & 75,0 \\
\hline & Multipara & 6 & 25,0 \\
\hline \multicolumn{4}{|l|}{ Pré-natal } \\
\hline \multirow[t]{2}{*}{ Local } & Rede pública & 18 & 75,0 \\
\hline & Rede privada & 6 & 25,0 \\
\hline \multirow[t]{3}{*}{$\mathrm{N}^{0}$ de consultas } & $\geq 6$ & 20 & 83,3 \\
\hline & $<6$ & 1 & 4,2 \\
\hline & Năo informado & 3 & 12,5 \\
\hline \multirow[t]{2}{*}{ Orientação sobre AM } & Sim & 8 & 33,3 \\
\hline & Não & 16 & 66,6 \\
\hline \multicolumn{4}{|l|}{ Parto } \\
\hline \multirow{2}{*}{ Tiрo } & Normal & 15 & 62,5 \\
\hline & Cesárea & 9 & 37,5 \\
\hline \multirow[t]{2}{*}{ Local } & Rede pública & 19 & 79,2 \\
\hline & Rede privada & 5 & 20,8 \\
\hline \multirow[t]{2}{*}{ Idade gestacional } & A termo ( $\geq 37$ sem) & 23 & 95,8 \\
\hline & Pré-termo & 1 & 4,2 \\
\hline
\end{tabular}

Fonte: elaborado pelos autores, 2018 
Figura 1. Fluxograma participantes artigo

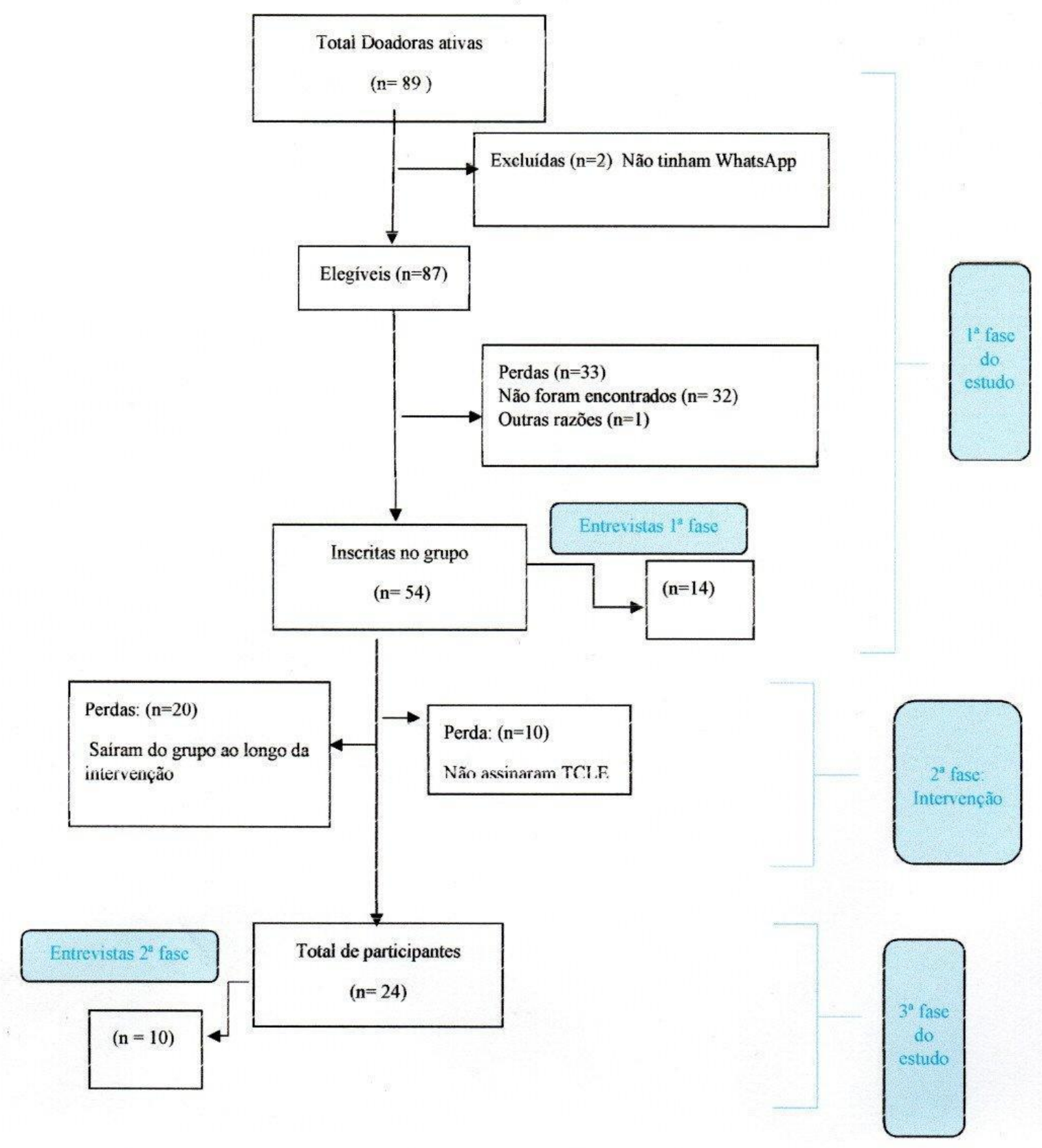

Fonte: Elaborado pelos autores, 2018. 